\title{
INEQUALITIES FOR SHEPARD-TYPE OPERATORS
}

\author{
U. Amato And B. Della Vecchia
}

Abstract. Direct and converse approximation error estimates for generalized Shepard operators are given, improving analogous inequalities for well-known Shepard operators. As application in CAGD, generalized degree elevation algorithms for modeling the shape of Shepard-type curves are presented, improving previous techniques.

Mathematics subject classification (2010): 41A36, 41A25, 65D17.

Keywords and phrases: Shepard-type operators, direct and converse results, saturation, Shepard-type curves, degree-elevation formula, progressive iterative approximation technique.

\section{REFERENCES}

[1] G. Allasia, A class of interpolatory positive linear operators: theoretical and computational aspects, Approximation Theory, Wavelets and Applications NATO ASI Series C 454, 1-36, Washington, 1995.

[2] G. Allasia, Cardinal basis interpolation on multivariate scattered data, Nonlinear Analysis Forum 6, 1 (2001), 1-13.

[3] U. Amato and B. Della Vecchia, New results on rational approximation, Results in Mathem. 67, 3-4 (2015), 354-364.

[4] U. Amato and B. Della Vecchia, Modelling by Shepard-type curves and surfaces, J. Comp. Anal. Applic. 20, 4 (2016), 611-634.

[5] U. Amato And B. Della Vecchia, Weighting Shepard-Type operators, Comput. Applied Mathem. 36, 2, (2017), 885-902.

[6] K. Anjyo, J.P. Lewis And F. Pighin, Scattered data interpolation for computer graphics, Proc. SIGGRAPH '14, New York, 2014.

[7] G. Criscuolo and G. Mastroianni, Estimates of the Shepard interpolatory procedure, Acta Math. Acad. Sci. Hungar. 61, 1-2 (1993), 79-91.

[8] B. Della VeCCHiA, Direct and converse results by rational operators, Constr. Approx. 12, 2 (1990), 271-286.

[9] B. Della Vecchia, G. Mastroianni And V. Totik, Saturation of the Shepard operators, Approx. Th. Appl. 6, 4 (1990), 76-84.

[10] B. Della Vecchia And I. Szalkai, Finding better weights functions for Generalized Shepard's operator on infinite intervals, Int. J. Comp. Math. 88, 13 (2011), 2838-2851.

[11] B. Della Vecchia, G. Mastroianni And J. Szabados, Approximation with exponential weights in $[-1,1]$, J. Math. Anal. Appl. 272, 1 (2002), 1-18.

[12] B. Della Vecchia, G. Mastroianni and J. Szabados, Weighted approximation of functions with inner singularities by exponential weights in $[-1,1]$, Numer. Funct. Anal. Optim. 24, 1-2 (2003), 181-194.

[13] Z. Ditzian And V. Totik, Moduli of smoothness, Springer Series in Computational Mathematics 9, New York, 1987.

[14] I. GonsKA AND I. RAŞA, The limiting semigroup of the Bernstein iterates: degree of convergence Acta Math. Hungar. 111, 1-2 (2006), 119-130.

[15] T. Herman And P. Vertesi, On the method of Somorjai, Acta Math. Hungar. 54, 3-4 (1989), $253-$ 262.

[16] L. LU, Weighted progressive iteration approximation and convergence analysis, Comp. Aided Geom. Design 27, 2 (2010), 129-137. 
[17] D. J. Newmann And T. J. Rivlin, Optimal universally stable interpolation, IBM Research Report RC 9751, New York, 1982.

[18] J. SZABADOS, Direct and converse approximation theorems for the Shepard operator, Approx. Theory Appl. 7, 3 (1991), 63-76.

[19] V. Tотік Approximation by Bernstein polynomials, Amer. J. Math. 116, 4 (1994), 995-1018.

[20] V. Tотік, An interpolation theorem and its applications to positive operators, Pacific J. Math. 111, 2 (1984), 447-481.

[21] P. VERTESI, Saturation of the Shepard operator, Acta Math. Hungar. 72, 4, (1996), 307-317.

[22] B. WÜNSCHE AND E. TEMPERO, A comparison and evaluation of interpolation methods for visualising discrete 2D survey data, Proc. APVis '04 2004 Australian Symposium on Information Visualization 35, 1-7, 2004. 